ARTICLE

\title{
Radiation-resistant metal-organic framework enables efficient separation of krypton fission gas from spent nuclear fuel
}

\author{
Sameh K. Elsaidi (10) 1,2,3凶, Mona H. Mohamed 4,5, Ahmed S. Helal ${ }^{6,7}$, Mitchell Galanek ${ }^{8}$, Tony Pham (1) 9,10, \\ Shanelle Suepaul ${ }^{10}$, Brian Space $\mathbb{1}^{10}{ }^{10}$, David Hopkinson ${ }^{3}$, Praveen K. Thallapally ${ }^{11 凶} \&$ Ju Li (i) ${ }^{7 凶}$
}

Capture and storage of volatile radionuclides that result from processing of used nuclear fuel is a major challenge. Solid adsorbents, in particular ultra-microporous metal-organic frameworks, could be effective in capturing these volatile radionuclides, including ${ }^{85} \mathrm{Kr}$. However, metal-organic frameworks are found to have higher affinity for xenon than for krypton, and have comparable affinity for $\mathrm{Kr}$ and $\mathrm{N}_{2}$. Also, the adsorbent needs to have high radiation stability. To address these challenges, here we evaluate a series of ultra-microporous metalorganic frameworks, SIFSIX-3-M (M=Zn, Cu, Ni, Co, or Fe) for their capability in ${ }^{85} \mathrm{Kr}$ separation and storage using a two-bed breakthrough method. These materials were found to have higher $\mathrm{Kr} / \mathrm{N}_{2}$ selectivity than current benchmark materials, which leads to a notable decrease in the nuclear waste volume. The materials were systematically studied for gamma and beta irradiation stability, and SIFSIX-3-Cu is found to be the most radiation resistant.

\footnotetext{
${ }^{1}$ Department of Chemical and Biomolecular Engineering, University of California, Berkeley, Berkeley, CA 94720, USA. ${ }^{2}$ Oak Ridge Institute for Science and Education, Pittsburgh, PA 15236, USA. ${ }^{3}$ DOE National Energy and Technology Laboratory (NETL), Pittsburgh, PA 15236, USA. ${ }^{4}$ Department of Chemistry, University of Pittsburgh, 219 Parkman Avenue, Pittsburgh, USA. ${ }^{5}$ Chemistry Department, Faculty of Science, Alexandria University, P.O. Box 426, Ibrahimia, Alexandria 21321, Egypt. ${ }^{6}$ Nuclear Materials Authority, P.O. Box 540, El Maadi, Cairo, Egypt. ${ }^{7}$ Department of Nuclear Science and Engineering and Department of Materials Science and Engineering, Massachusetts Institute of Technology, Cambridge, MA 02139, USA. ${ }^{8}$ Office of Environment, Health \& Safety, Massachusetts Institute of Technology, Cambridge, MA 02139, USA. ${ }^{9}$ Department of Chemistry, Biochemistry, and Physics, The University of Tampa, 401 West Kennedy Boulevard, Tampa, FL 33606-1490, USA. ${ }^{10}$ Department of Chemistry, University of South Florida, 4202 East Fowler Avenue, CHE205, Tampa, FL 33620, USA.

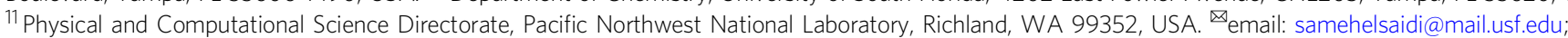
Praveen.thallapally@pnnl.gov; liju@mit.edu
} 
$\mathrm{N}$ uclear energy is an emission free, high-energy density source with minimal land use. However, any future expansion of civilian nuclear power will most likely require efficient management of used nuclear fuel (UNF). UNF processing minimizes radioactive waste, but the release of volatile radionuclides is a significant challenge. The nature of the volatile radionuclides depends on the reprocessing procedure and generally consists of a mixture of noble gases (predominantly ${ }^{85} \mathrm{Kr}$, which $\beta$ or $\beta \gamma$ decays to stable ${ }^{85} \mathrm{Rb}$ with $t_{1 / 2}=10.8$ years, along with $\mathrm{Xe}$ ), and species containing ${ }^{129} \mathrm{I}^{1-5}$. The current reprocessing technologies can capture other volatile radionuclides with relative ease, but an efficient system to capture (and store) ${ }^{85} \mathrm{Kr}$ needs to be in place. While methods such as cryogenic distillation and fluorocarbon based absorption have been proposed and tested, they are expensive and require complex engineering control. Solid-state adsorbents, in particular porous metal-organic frameworks (MOFs), could be better alternatives to capture these volatile radionuclides including ${ }^{85} \mathrm{Kr}$.

Physisorption-based adsorption and storage is deemed an energy-efficient process that can be operated at near-ambient conditions and is easier to integrate into current engineering setups. Several traditional adsorbents such as zeolites and activated carbon have been tested, but were found to have low capacity and selectivity (over Xe and other competing gases). MOFs are known for their versatile architecture and functionalized pore surface and have shown promise for gas sorption and separation ${ }^{1,6-16}$. However, as Xe is considerably more polarizable than $\mathrm{Kr}$, porous materials such as MOFs are generally more selective toward $\mathrm{Xe}$ over $\mathrm{Kr}$ due to stronger van der Waals interactions, which causes further engineering challenges as the $\mathrm{Xe}$ will lead to reduced $\mathrm{Kr}$ adsorption ${ }^{2,7,15,17-19}$. To avoid this, we recently reported a proof-of-concept study where a dual-bed system, fitted in series, was utilized to separate and store $\mathrm{Kr}^{20}$. The gas stream (known as off-gas, $400 \mathrm{ppm}$ of Xe and $40 \mathrm{ppm}$ of $\mathrm{Kr}$ mixed with air, which are the typical concentrations of the offgas in a reprocessing plant) is first directed through a Xe selective adsorbent bed to remove the $\mathrm{Xe}$, followed by removal of $\mathrm{Kr}$ in the second bed using the same or another adsorbent material. In the absence of the competing $\mathrm{Xe}$ in the second bed, the adsorbent is expected to have enhanced $\mathrm{Kr}$ storage capacity, even when using identical adsorbent material (which is the modality used in this paper). The enhancement and the total $\mathrm{Kr}$ uptake depend on the selectivity for $\mathrm{Kr}$ over competing gases (e.g., $\mathrm{N}_{2}, \mathrm{O}_{2}$ ). The stored gas in the second bed has a high $\mathrm{Kr}$, low $\mathrm{Xe}$ feature, so the second bed can be fluidized and/or regenerated (with temperature controlled desorption) with such characteristics in mind. The MOFs in both the first bed and the second bed should be sufficiently radiation resistant to beta and gamma radiations as ${ }^{85} \mathrm{Kr}$ flows pass or stores in them. Only a few MOFs have been studied for their radiation stability ${ }^{20,21}$. Lee et al. reported the potential of three MOFs (MIL-100(Fe), MIL-101(Cr), and UiO-66(Zr)) for $\mathrm{Xe} / \mathrm{Kr}$ separation ${ }^{22}$. The study showed that $\mathrm{UiO}-66(\mathrm{Zr})$ is the most promising adsorbent among the three candidates; however, the radiation stability of $\mathrm{UiO}-66(\mathrm{Zr})$ has been performed under low radiation dose of only $2 \mathrm{kGy}$ which is not relevant to the practical $\mathrm{Xe} / \mathrm{Kr}$ separation at nuclear reprocessing plants.

In our continuous search for materials with high $\mathrm{Kr}$ adsorption capacity and selectivity, we synthesized, measured and analyzed the SIFSIX-3-M series ( $\mathrm{M}=\mathrm{Zn}, \mathrm{Cu}, \mathrm{Ni}, \mathrm{Co}, \mathrm{Fe})$ of $\mathrm{MOFs}^{7,23-25}$. SIFSIX-3-M is a class of isoreticular hybrid ultra-microporous materials (HUMs) based on saturated metal centers (SMCs) and $\mathrm{SiF}_{6}{ }^{-2}$ pillars ${ }^{26,27}$. SIFSIX-3-M can be tuned for $\mathrm{Kr}$ separation by substituting different metal centers including $\mathrm{Zn}^{27,28}, \mathrm{Co}^{29}, \mathrm{Cu}^{30}$, $\mathrm{Ni}^{29}$, or $\mathrm{Fe}^{8}$. SIFSIX-3-M materials are known for their very low affinity toward $\mathrm{N}_{2}$ and for exceptional performance in selectively removing $\mathrm{CO}_{2}$ from air, which makes them great candidates for two-bed breakthrough setup. In this study, two columns were filled by adsorbent material that has a preferential adsorption of gases $\mathrm{Xe}, \mathrm{CO}_{2}>\mathrm{Kr}>\mathrm{N}_{2}$ and $\mathrm{O}_{2}$. The $\mathrm{Xe}$ and $\mathrm{CO}_{2}$ gases will be selectively adsorbed over the rest of gases in the first bed while the $\mathrm{Kr}$ will be preferentially adsorbed over the $\mathrm{N}_{2}$ and $\mathrm{O}_{2}$ in the second bed. The advantage of this method is that we can separate the radioactive ${ }^{85} \mathrm{Kr}$ into a high purity gas. The presence of other gases mixed with ${ }^{85} \mathrm{Kr}$ would otherwise increase the waste volume to be disposed and therefore increase the cost of the UNF reprocessing (Fig. 1).

\section{Results}

Radiation stability study. The MOF materials were exposed to gamma radiation $\left({ }^{60} \mathrm{Co}\right.$ source) from 0 to $200 \mathrm{kGy}$ and the stability of the materials was monitored by powder X-ray diffraction (PXRD) to confirm the retention of their crystallinity after $\gamma$ irradiation (see Methods section for experimental details) and $\beta$ irradiation. The near equivalence in radiation damage tolerance dose between ${ }^{85} \mathrm{Kr} \beta$ and ${ }^{60} \mathrm{Co} \gamma$-rays was well established, for example "no significant difference in the decomposition yield was observed" in fluorocarbons exposed to beta and gamma radiation of the same dose $\mathrm{e}^{31}$.

Quantitative analyses of the PXRD data using the Rietveld and Pawley fitting methods were performed to compare the assynthesized structures with the irradiated structures (Supplementary Figs. 3-17). As shown in Figs. 2 and 3 and Supplementary Figs. 3 and 4, the $\mathrm{Zn}$ and $\mathrm{Ni}$ analogs are unstable and show phase change at $1 \mathrm{kGy}$. SIFSIX-3-Fe maintained its crystallinity at $1 \mathrm{kGy}$. Further irradiation of SIFSIX-3-Fe to 3 and $10 \mathrm{kGy}$ leads to new unknown phases as shown in Supplementary Figs. 4-8. The new phase is a mixture of a $1 \mathrm{D}$ structure with water coordinated to $\mathrm{Fe}$ (Fig. 2) and another unknown phase. The original structure of SIFSIX-3-Fe is strongly distorted and almost vanished. The SIFSIX3-Co structure was stable up to $10 \mathrm{kGy}$ before it undergoes phase change (Supplementary Figs. 9-12). From the PXRD pattern of irradiated MOF at $3 \mathrm{kGy}$, higher peak intensity for the (110) peak at $17.65^{\circ}$ was observed which may be attributed to spinning of fluorine atoms into the (110) plane (Supplementary Fig. 11). Based on these results the crystal structure of SIFSIX-3-Co remains unaltered under $3 \mathrm{kGy}$ radiation. After $10 \mathrm{kGy}$ radiation, the crystal structure is altered and presents the original SIFSIX-3-Co structure as well as another unknown phase. The unit cell and space group are determined from the unknown phase peak positions (Supplementary Fig. 12) to be tetragonal $(4 / \mathrm{m})$ with lattice parameters $a=16.086 \AA$ and $c=12.952 \AA$, which does not exist in the CCDC database ${ }^{32}$.

SIFSIX-3-Cu was the most stable MOF (Supplementary Figs. 13-17) and it maintained its crystallinity up to $50 \mathrm{kGy}$ $\gamma$ irradiation. According to Cambridge Structural Database $(\mathrm{CSD})^{33}, \mathrm{Cu}$ tends to bond with $\mathrm{N}$ donor ligand more readily compared with $\mathrm{Co}, \mathrm{Fe}, \mathrm{Zn}$, and $\mathrm{Ni}$. The $\mathrm{Cu}-\mathrm{N}$ bonds are stronger than those of other $\mathrm{M}-\mathrm{N}$ analogs. This is supported by shorter $\mathrm{Cu}-\mathrm{N}$ bond distance of $1.9 \AA$ in the SIFSIX-3-Cu compared with the other the $\mathrm{M}-\mathrm{N}$ analogs $(2.1 \AA)$. Also, it was reported that the SIFSIX-3-Cu has a slightly smaller unit cell of $378 \AA^{3}$ versus $388 \AA^{3}$ (SIFSIX-3-Zn), where the authors attributed this observation to the relatively stronger bonding between the $\mathrm{Cu}(\mathrm{II})$ and the pyrazine ${ }^{30}$. Therefore, $\mathrm{M}-\mathrm{N}$ bond strength could be the main factor behind the stability of SIFSIX-3-Cu framework which reaches up to $50 \mathrm{kGy}$, while other materials demonstrate much lower stability that reaches to maximum $10 \mathrm{kGy}$ (in case of Co). For this class of the isoreticular SIFSIX-3-M structures, it was reported that the change in metal center or the environment around it could lead to different properties of the MOF material ${ }^{8,21,29,30,34}$. 


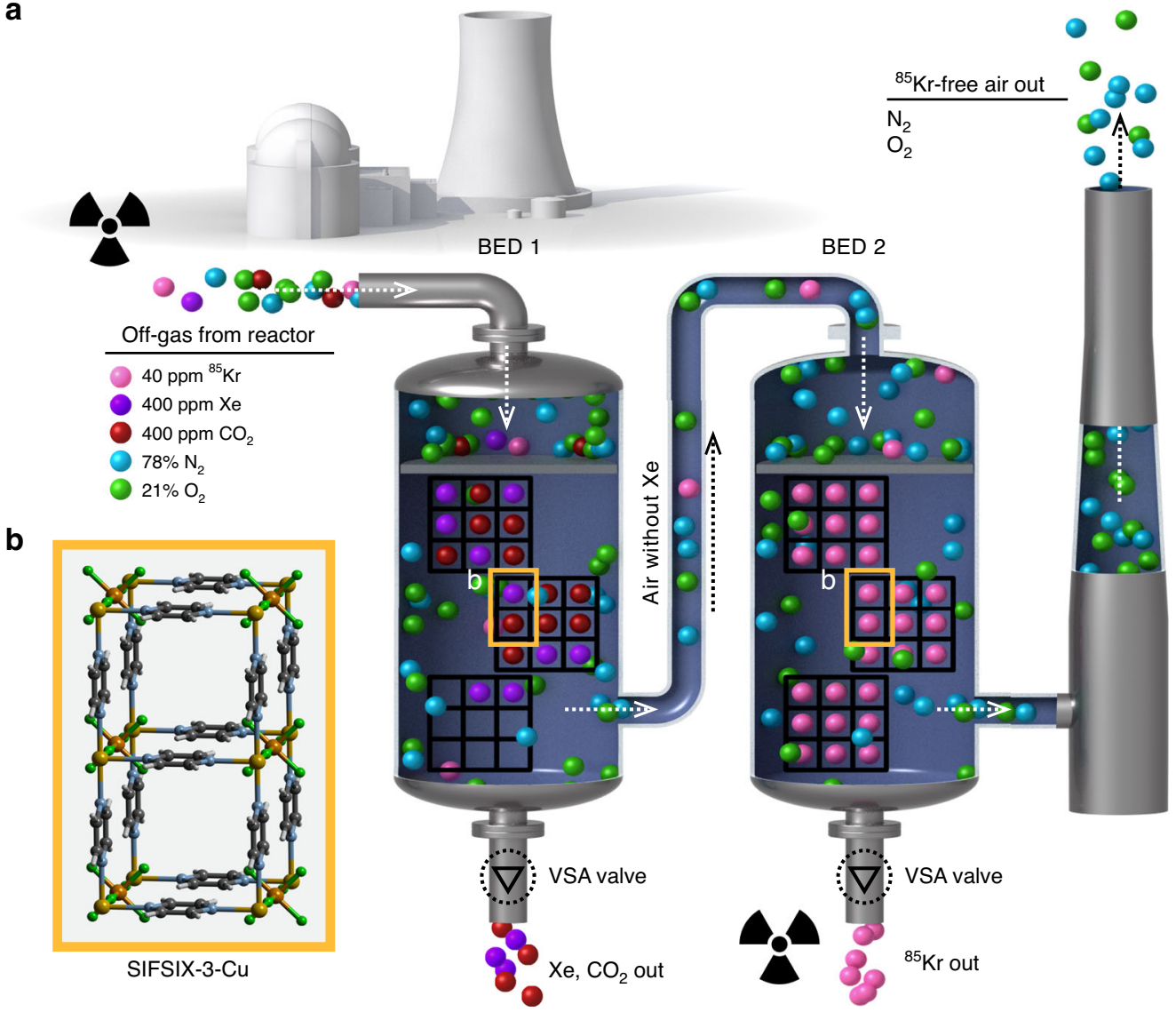

Fig. 1 Schematic representation of the two-bed breakthrough setup. a Illustration of the two-bed technique for removal of radioactive $\mathrm{Kr}$ from nuclear reprocessing plants using SIFSIX-3-Cu. b Each two squares in the bed 1 and bed 2 represent two channels of SIFSIX-3-Cu structure. Atom colors: $\mathrm{C}=$ gray, $\mathrm{H}=$ white, $\mathrm{N}=$ light blue, $\mathrm{F}=$ green, $\mathrm{Si}=$ light brown, $\mathrm{Cu}=$ orange, $\mathrm{O}=$ red, $\mathrm{Xe}=$ violet, $\mathrm{Kr}=$ pink.

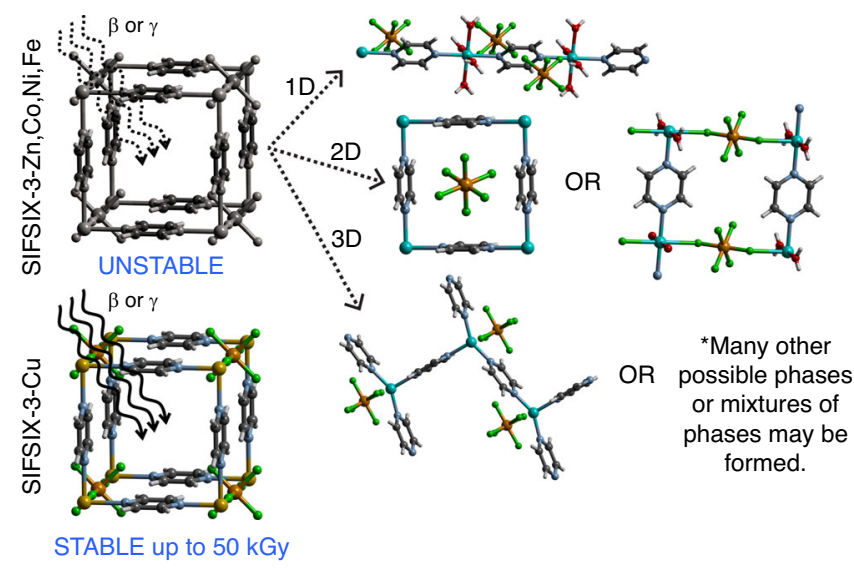

Fig. 2 Illustration of impact of irradiation on SIFSIX-3-M materials. The SIFSIX-3-M ( $M=\mathrm{Zn}, \mathrm{Co}, \mathrm{Ni}, \mathrm{Fe})$ structures decompose to 1D, 2D or many other possible phases up on radiation exposure. The SIFSIX-3-Cu is stable and maintains its original crystal structure up to $50 \mathrm{kGy}$ dose in beta or gamma radiation. Atom colors: $\mathrm{C}=$ gray, $\mathrm{H}=$ white, $\mathrm{N}=$ light blue, $\mathrm{F}=$ green, $\mathrm{Si}=$ light brown, $\mathrm{Cu}=$ orange, $\mathrm{M}(\mathrm{Ni}, \mathrm{Co}, \mathrm{Fe}, \mathrm{Zn})=$ cyan, $\mathrm{O}=$ red.

The beta radiation stability of the SIFSIX-3-Cu was evaluated by irradiating the activated sample with $1.5 \mathrm{MeV}$ electrons beam at a dose rate of $50 \mathrm{kGy} / \mathrm{h}$ and comparing its PXRD pattern with the simulated SIFSIX-3-Cu pattern. Figure $3 \mathrm{f}$ showed that the activated SIFSIX-3-Cu sample is stable after $50 \mathrm{kGy}$ beta irradiation. ${ }^{85} \mathrm{Kr}$ concentration is reported to be $1130-1800$ $\mathrm{TBq} / \mathrm{Mg}(3510-48,600 \mathrm{Ci} / \mathrm{Mg})$ of spent fuel ${ }^{35}$. Based on these concentrations, the radiation dose rate to $1 \mathrm{~g}$ SIFSIX-3- $\mathrm{Cu}$ from absorbing all the ${ }^{85} \mathrm{Kr}$ in $1 \mathrm{~g}$ of spent nuclear fuel was calculated (see Supplementary Note 3). According to the obtained results from both beta and gamma irradiation experiments, SIFSIX-3-Cu is radiation resistant up to $50 \mathrm{kGy}$. Hence, $1 \mathrm{~g}$ of SIFSIX-3-Cu can separate ${ }^{85} \mathrm{Kr}$ effectively from $2674 \mathrm{~g}$ of spent nuclear fuel (130 TBq/Mg case) or $188 \mathrm{~g}$ spent nuclear fuel $(1800 \mathrm{TBq} / \mathrm{Mg}$ case), without any crystal structure damage, if keeping all the ${ }^{85} \mathrm{Kr}$ inside for $1 \mathrm{~h}$.

Single-component gas adsorption study. The single-component $\mathrm{CO}_{2}$, $\mathrm{Xe}, \mathrm{Kr}, \mathrm{N}_{2}$, and $\mathrm{O}_{2}$ adsorption isotherms of SIFSIX-3-Cu at $298 \mathrm{~K}$ (Fig. 4a) showed a preferential adsorption of $\mathrm{CO}_{2}$ and $\mathrm{Xe}$ over $\mathrm{Kr}$ which will allow $\mathrm{CO}_{2}$ and $\mathrm{Xe}$ capture in the first bed, and a high $\mathrm{Kr} / \mathrm{N}_{2}$ selectivity which facilitates the capture of the ${ }^{85} \mathrm{Kr}$ in the second bed.

Modeling study. As revealed through modeling studies, the larger atomic radius for Xe provided for a better fit within the square pores as well as the region enclosed by four neighboring $\mathrm{SiF}_{6}{ }^{2-}$ pillars in the material (Fig. 4b, c and Supplementary Figs. 23 and 24). Furthermore, density functional theory (DFT) calculations confirm that SIFSIX-3-Cu is selective for $\mathrm{CO}_{2}$ and Xe over $\mathrm{Kr}$, and $\mathrm{Kr}$ over $\mathrm{N}_{2}$ and $\mathrm{O}_{2}$ on the basis of the DFT calculated adsorption energies in the material (see Supplementary Note 5 and Supplementary Table 1). 

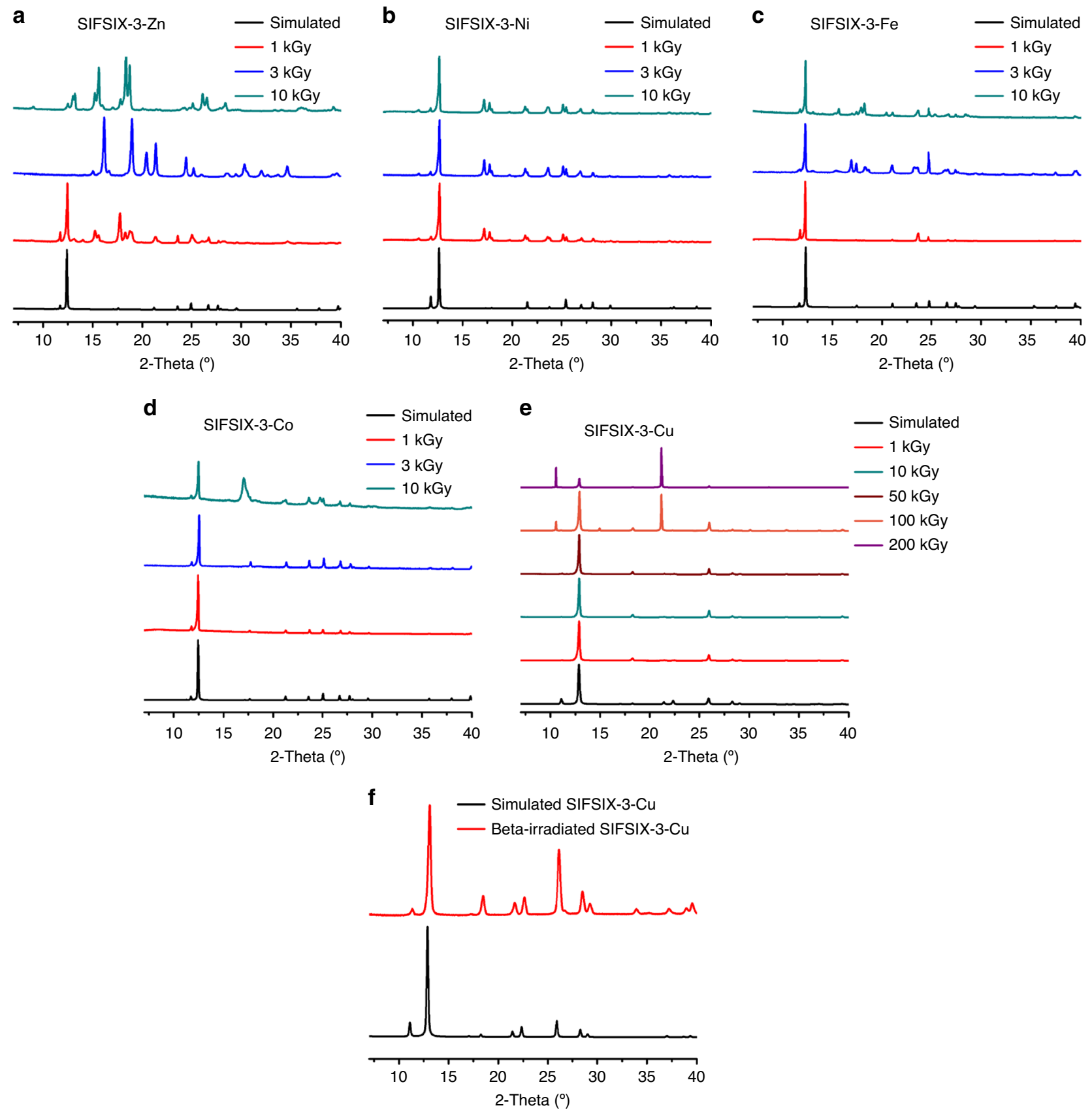

Fig. 3 Powder X-ray diffraction patterns of irradiated and simulated SIFSIX-3-M structures. a gamma-irradiated SIFSIX-3-Zn, b gamma-irradiated SIFSIX-3-Ni, c gamma-irradiated SIFSIX-3-Fe, d gamma-irradiated SIFSIX-3-Co, and e SIFSIX-3-Cu and $\mathbf{f}$ activated SIFSIX-3-Cu structure after 50 kGy beta irradiation.

Two-bed breakthrough adsorption study. We ran the two-bed breakthrough experiments, where both beds use SIFSIX-3-Cu, because of its high radiation stability (Fig. 3e). First, a single-bed test was performed on SIFSIX-3-Cu (Fig. 5a, b) in order to show the ability of SIFSIX-3-Cu for separation of $\mathrm{Kr}$ gas from $\mathrm{N}_{2}$ and $\mathrm{O}_{2}$. Second, single-bed experiments were run for the simulated off-gas containing 400 ppm Xe and 40 ppm Kr balanced with dry air, revealing the time needed for each gas to break through from the first bed under the conditions of simulated off-gas stream. Accordingly, this information informed us of when to switch on the second bed in the two-bed system before $\mathrm{Xe}$ and $\mathrm{CO}_{2}$ start to break through (see Fig. 1, Supplementary Note 6 and Supplementary Scheme 1). The single-bed breakthrough experiments for 1000 ppm Kr balanced with dry air revealed that SIFSIX-3-Cu can selectively adsorb $\mathrm{Kr}$ over $\mathrm{N}_{2}$ and $\mathrm{O}_{2}$ as shown in Fig. 5 and Table 1.

Based on the single-column experiment, SIFSIX-3-Cu can selectively separate Xe from gas mixture 1 consisting of $400 \mathrm{ppm}$ $\mathrm{Xe}, 40 \mathrm{ppm} \mathrm{Kr}$ balanced with dry air. The column breakthrough experiment suggests that Xe breakthrough occurs at $t_{1}$ finish $=29$ min, thus by connecting a second bed loaded with adsorbent material before this time, we will be able to capture the $\mathrm{Kr}$ in the second bed before the Xe breaks through the first bed (see Fig. 5). We note that $t_{1}$ finish certainly depends on the size and geometric design of the first bed (which can be fluidized ${ }^{36}$ ), i.e., it is not just a material property.

The two-column breakthrough system consists of two adsorption beds in series that were packed with $1 \mathrm{~g}$ of SIFISIX-3-Cu in 
a

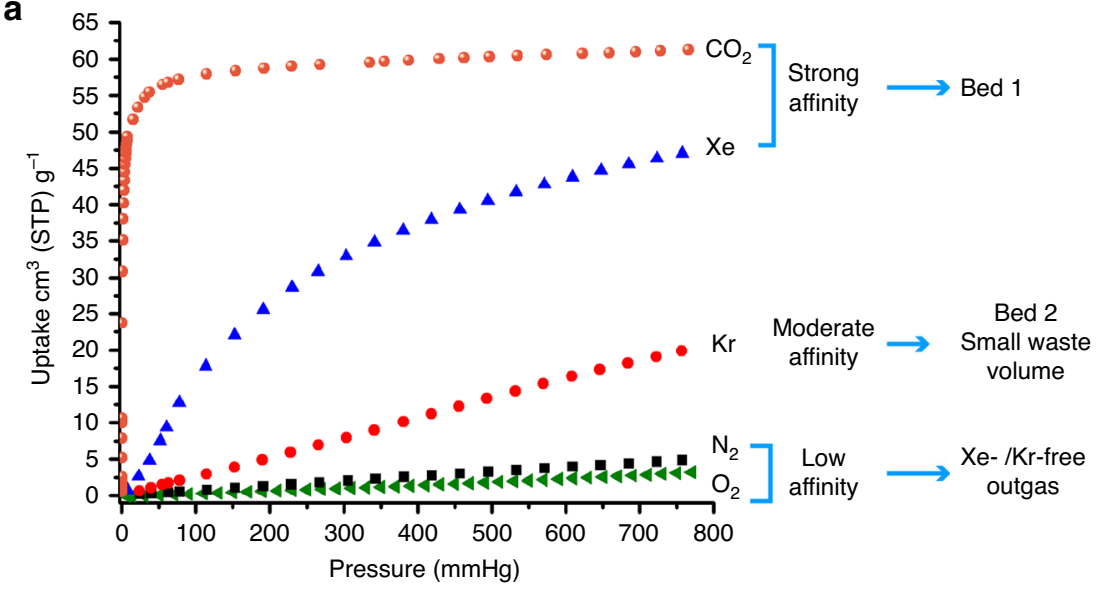

b

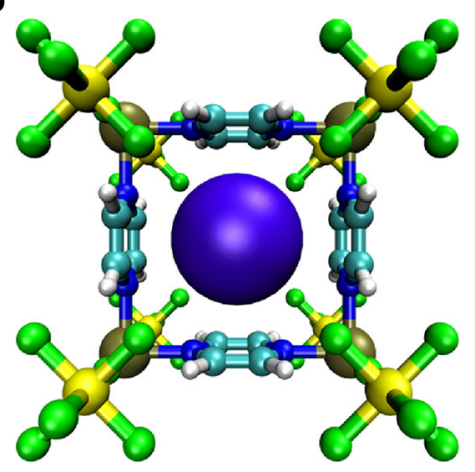

C

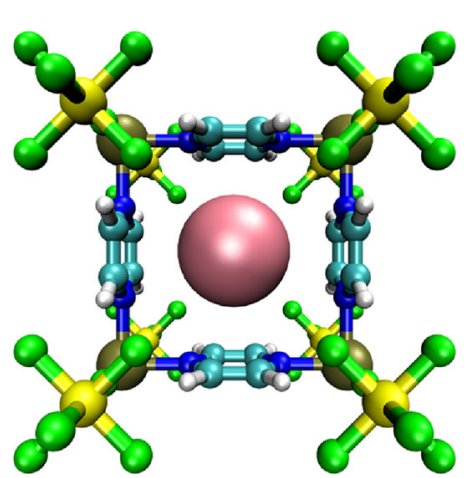

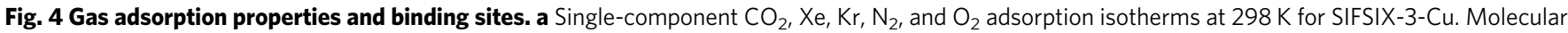
illustration of the most favorable binding site for $\mathbf{b}$ Xe and $\mathbf{c} \mathrm{Kr}$ in SIFSIX-3-Cu (top view) as determined from simulated annealing calculations. Atom colors: $\mathrm{C}=$ cyan, $\mathrm{H}=$ white, $\mathrm{N}=$ blue, $\mathrm{F}=$ green, $\mathrm{Si}=$ yellow, $\mathrm{Cu}=$ gold, $\mathrm{Xe}=$ violet, $\mathrm{Kr}=$ pink.

each bed. The adsorbent beds were purged with $\mathrm{He}$ and then a gas mixture containing $400 \mathrm{ppm} \mathrm{Xe}$ and $40 \mathrm{ppm} \mathrm{Kr}$ balanced with dry air at a total pressure of 1 bar was introduced to the first bed (with the second bed bypassed). Breakthrough curves indicate that the $\mathrm{Xe}$ gas and $\mathrm{CO}_{2}$ were retained by the first bed, leaving $40 \mathrm{ppm} \mathrm{Kr}$ balanced with dry air at the outlet. At time $t_{2}{ }^{\text {start }}=18$ min, the second bed was enabled, thus flowing gas from the first bed to the second. Gas analysis shows that $\mathrm{Kr}$ concentration drops as it is adsorbed into the second bed, and fully breaks through again at $t_{2}{ }_{\text {finish }}=$ around $30 \mathrm{~min}$. In practice the feed gas would be directed to a new bed, while the $\mathrm{Kr}$ loaded bed is regenerated. It is important to note that the adsorbent material can capture $\mathrm{Kr}$ gas over the competing gases that could increase the waste volume. The benchmark materials, SBMOF-1 ${ }^{37}, \mathrm{Ni}$ MOF- $74^{38}$, and Ag mordenite ${ }^{39}$, showed remarkable performance for $\mathrm{Xe} / \mathrm{Kr}$ separation, however, they are not suitable for ${ }^{85} \mathrm{Kr}$ separation from spent fuel using the two-bed technique. NiMOF- $74^{38}$ and $\mathrm{Ag}$ mordenite ${ }^{39}$ were found to have poor $\mathrm{Kr} / \mathrm{N}_{2}$ selectivity (Supplementary Figs. 21 and 30), while, SBMOF-137 showed low $\mathrm{Kr} / \mathrm{CO}_{2}$ which prohibit the separation of the $\mathrm{Kr}$ in pure form (Supplementary Fig. 22).

As shown in Fig. 5 and Table 1, SIFISIX-3-Cu showed a great potential for $\mathrm{Kr}$ removal from simulated UNF off-gas using the two-bed system. The calculated capacity of the adsorbed Xe in first bed by SIFSIX-3-Cu at equilibrium was found to be $6.74 \mathrm{mmol} / \mathrm{kg}$ while the capacity of the $\mathrm{Kr}$ captured in second bed is $0.15 \mathrm{mmol} / \mathrm{kg}$. This system is a feasible and efficient way to separate and capture $\mathrm{Xe}$ and $\mathrm{Kr}$ at ambient conditions. This further demonstrates that once the competing gas, $\mathrm{Xe}$, is removed in the first bed using SIFSIX-3-Cu, the $\mathrm{Kr}$ removal efficiency was increased significantly, which can lead to a notable decrease in the waste volume at the UNF reprocessing plant.

\section{Discussion}

In summary, we evaluated the performance of a family of ultramicroporous pillared square lattices, SIFSIX-3-M $(\mathrm{M}=\mathrm{Fe}, \mathrm{Co}$, $\mathrm{Ni}, \mathrm{Cu}, \mathrm{Zn}$ ) for ${ }^{85} \mathrm{Kr}$ removal from used nuclear fuel. The radiation stability was examined by exposing the materials to varying levels of gamma radiation and beta radiation.

SIFSIX-3-Cu is the only material in this family suitable for this application based on radiation stability up to $50 \mathrm{kGy}$ for both beta and gamma radiations.

The choice of the right material for the ${ }^{85} \mathrm{Kr}$ separation from nuclear reprocessing plants is based on several criteria: (1) Preferential adsorption of $\mathrm{Xe}$ and $\mathrm{CO}_{2}$ over $\mathrm{Kr}$ so these two gases can be separated in the first bed, and (2) Preferential adsorption of $\mathrm{Kr}$ over $\mathrm{N}_{2}$ and $\mathrm{O}_{2}$ so that $\mathrm{Kr}$ can be adsorbed in the second bed in more pure form with minimum waste volume. If the material fulfills these two criteria, then it should be qualified for the radiation stability. If the material does not achieve these two criteria, it is not helpful in this context to examine their radiation stability because they did not fulfill the main purpose of the $\mathrm{Kr}$ removal presented herein, which is the reduction of waste volume and $\mathrm{Kr}$ separation in more pure form with minimal amounts of other competing gases.

The single-component adsorption isotherms revealed that SIFSIX-3-Cu can preferentially adsorb $\mathrm{CO}_{2}$ and $\mathrm{Xe}$ over $\mathrm{Kr}$, and $\mathrm{Kr}$ over $\mathrm{N}_{2}$ and $\mathrm{O}_{2}$; these findings have been supported by modeling. The practical use of SIFSIX-3-Cu in $\mathrm{Kr}$ capture and separation from nuclear fuel reprocessing off-gas was 
a

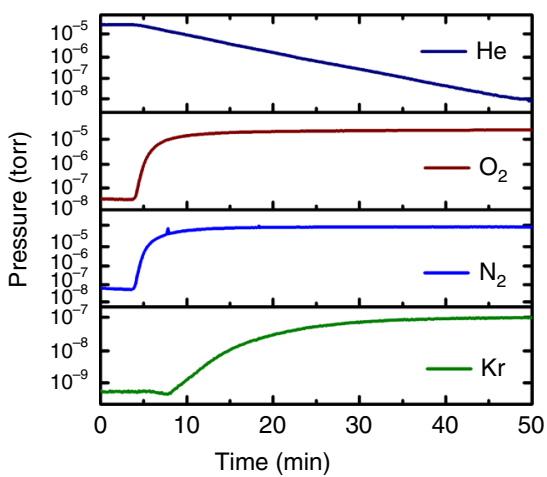

b

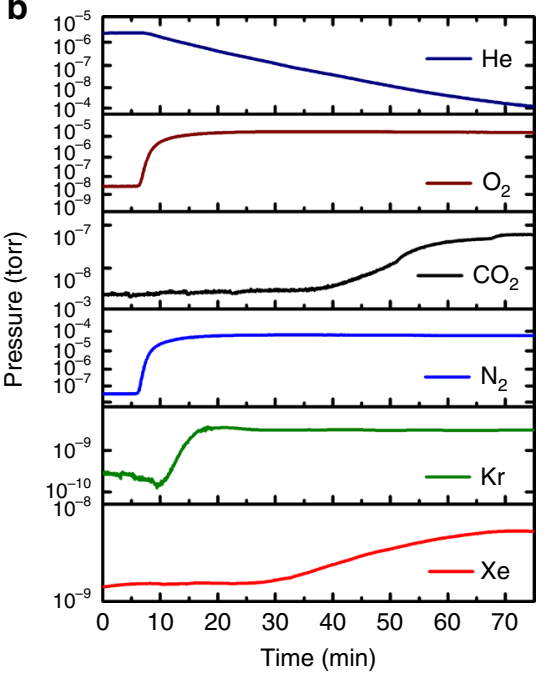

C

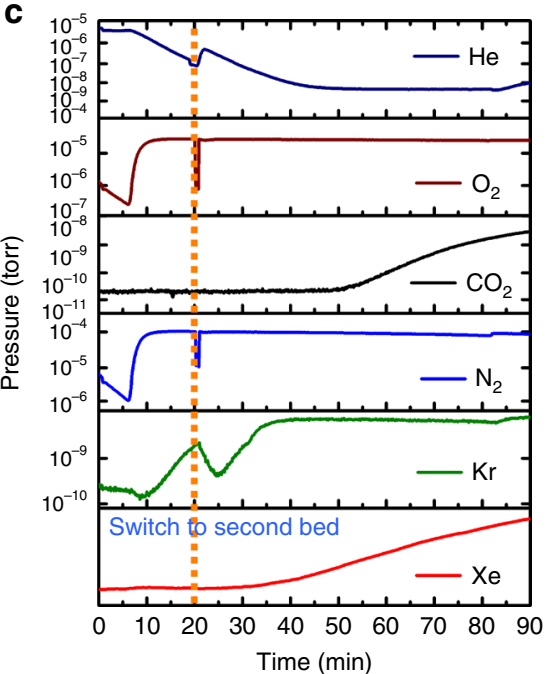

d

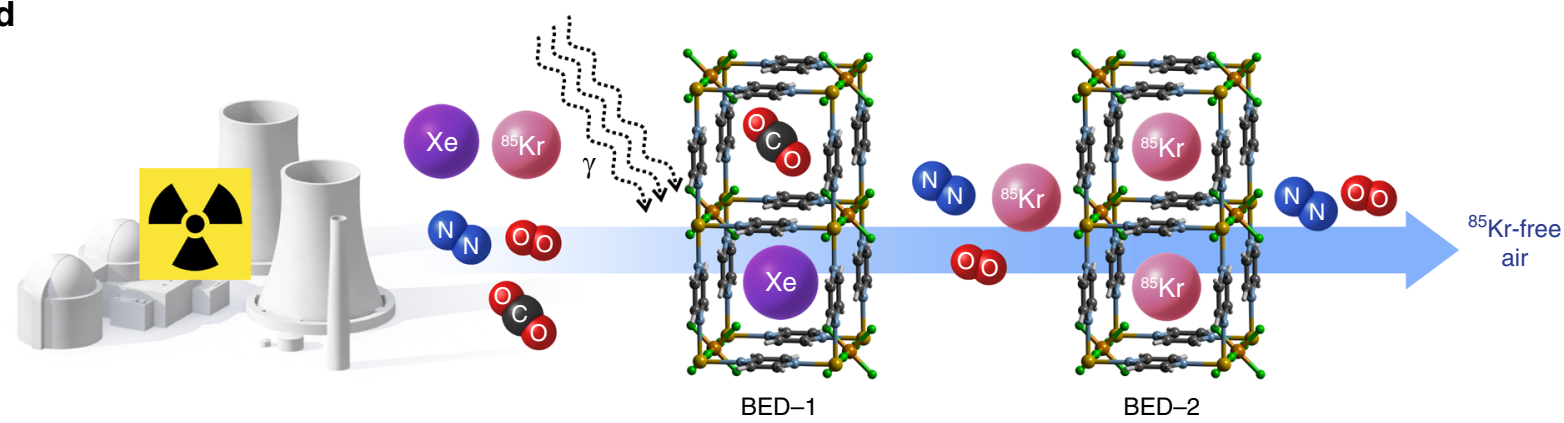

Fig. 5 Breakthrough curves for SIFSIX-3-Cu. a Single-bed breakthrough experiment using 1000 ppm Kr balanced with dry air. b Single-bed breakthrough experiment using $400 \mathrm{ppm} \mathrm{Xe}$ and $40 \mathrm{ppm} \mathrm{Kr}$ balanced with dry air. c Two-bed breakthrough experiment using 400 ppm Xe and 40 ppm Kr balanced with dry air. $\mathbf{d}$ schematic demonstration of the concept of the two-bed technique for the ${ }^{85} \mathrm{Kr}$ removal from the UNF.

\section{Table $1 \mathrm{Xe}$ and $\mathrm{Kr}$ separation performance parameters for SIFSIX-3-Cu at $298 \mathrm{~K}$ and 1 bar.}

\section{Material}

SIFSIX-3-Cu

Xe capacitya $(\mathrm{mmol} / \mathrm{kg})$

6.74

$\mathrm{Kr}$ capacity ${ }^{\mathrm{b}}(\mathrm{mmol} / \mathrm{kg})$

$\mathrm{Kr}$ capacity ${ }^{\mathrm{c}}(\mathrm{mmol} / \mathrm{kg})$

$\mathrm{Kr}$ capacity ${ }^{\mathrm{d}}(\mathrm{mmol} / \mathrm{kg})$

0.14

0.15

6.35

4.81

$\mathrm{Kr} / \mathrm{N}_{2}$ selectivity ${ }^{\dagger}$

24.38

Gas mixture 1: $400 \mathrm{ppm} \mathrm{Xe,} 40 \mathrm{ppm} \mathrm{Kr}$, balanced with dry air

axe capacity at equilibrium in bed 1 for gas mixture 1 .

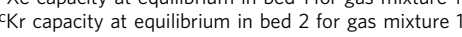

eXe/ $\mathrm{Kr}$ selectivity at equilibrium for bed 1 .

Gas mixture 2: $1000 \mathrm{ppm} \mathrm{Kr}$, balanced with dry air

${ }^{b} \mathrm{Kr}$ capacity at equilibrium in bed 1 for gas mixture 1 .

${ }^{d} \mathrm{Kr}$ capacity at equilibrium for gas mixture 2 .

${ }^{\mathrm{f}} \mathrm{Kr} / \mathrm{N}_{2}$ selectivity at equilibrium for gas mixture 2 .

demonstrated by using a two-bed breakthrough technique at ambient conditions. SIFSIX-3-Cu successfully captures $\mathrm{Xe}$ in the first bed, while high purity $\mathrm{Kr}$ gas is captured in the second bed using the same material. We attribute the remarkable performance of SIFSIX-3-M family to the narrow pore size as well as the high polarizability of $\mathrm{SiF}_{6}{ }^{-2}$ anions. Indeed, modeling studies revealed that the adsorbate localizes between four neighboring $\mathrm{SiF}_{6}{ }^{2-}$ pillars within the small pores in this class of materials.

\section{Methods}

Synthesis. $\left[\mathrm{M}(\mathrm{pyz})_{2} \mathrm{SiF}_{6}\right]$ (SIFSIX-3-M, M $=\mathrm{Zn}, \mathrm{Cu}, \mathrm{Ni}, \mathrm{Co}, \mathrm{Fe}$ ) was synthesized by dissolving $10 \mathrm{mmol}$ of pyrazine ligand (pyz) and $5 \mathrm{mmol}$ of $\mathrm{MSiF}_{6}$ salt in $23 \mathrm{~mL}$ of methanol and heating the resulting solution at $75^{\circ} \mathrm{C}$ for 3 days in a stainless steel Parr autoclave $e^{8,29}$. SIFSIX-3-Zn and SIFSIX-3-Co afford colorless and red crystals, respectively; while SIFSIX-3-Cu, SIFSIX-3-Ni, and SIFSIX-3-Fe afford blue, pale blue, and yellow crystalline powders, respectively. All structures possess six coordinated saturated metal centers that serve as 6-connected nodes with pcu topology through four equatorial pyrazine linkers and 2 axial $\mathrm{SiF}_{6}{ }^{-2}$ anion pillars to form the $3 \mathrm{D}$-pillared square-grid nets.

Gamma irradiation measurements. The MIT gamma irradiation facility, managed by the MIT Radiation Protection Program (RPP), houses a Gammacell 220 Excel self-shielded high dose-rate gamma ray irradiator (Supplementary Fig. 1) manufactured by MDS Nordion. The unit was manufactured in Canada by MDS Nordion on 13/10/2003 and contained an initial quantity of Cobalt-60 of 23,654 Curies (375.2 TBq) (Supplementary Fig. 2). The Co-60 sources are contained within a lead biological shield which allows for the safe use of the irradiator by trained radiation workers.

The Co-60 sources are arranged in a circle allowing for a uniform dose to the materials being irradiated. The samples ae loaded in the sample irradiation chamber and lowered by elevator to the Co- 60 source array. The inside dimensions of the chamber are 6.10 in $(15.49 \mathrm{~cm})$ diameter and 8.06 in $(20.47 \mathrm{~cm})$ high. The current chamber dose rate is $4235 \mathrm{Rads} / \mathrm{min}(42.35 \mathrm{~Gy} / \mathrm{min})$. The original chamber dose rate was $32,228 \mathrm{Rads} / \mathrm{min}(322.28 \mathrm{~Gy} / \mathrm{min})$.

Beta irradiation measurements. Experiments were performed at MIT's High Voltage Research Laboratory (HVRL), which houses a continuous-wave Van de Graaff electron accelerator capable of producing electron kinetic energies of $1.5-3.0 \mathrm{MeV}$ at beam currents of up to $30 \mu \mathrm{A}$. Samples were irradiated with $1.5 \mathrm{MeV}$ electrons beam at a dose rate of $50 \mathrm{kGy} / \mathrm{h}$. 
Powder X-ray diffraction measurements after gamma irradiation. The powder X-ray diffraction (PXRD) was collected on the PANalytical X'Pert Pro using $1.8 \mathrm{~kW}$ sealed X-ray tube source and $\mathrm{Cu}$ target. In order to solve the XRD data we use high score plus program to open the data and we used Rietveld and Pawley fitting methods.

\section{Data availability}

All data needed to evaluate the conclusions of this paper are present in the paper and/or Supplementary Information. The source data underlying Figs. $3 a-f, 4 a$, and $5 a-c$ and Supplementary Figs. 3-7, 9, 10, 12-17, 19-22, and 30, CAR files that were used to make the different binding site pictures in Supplementary Figs. 23-29 and XYZ files containing the atomic coordinates corresponding to the $\mathrm{Xe}$ and $\mathrm{Kr}$ binding site pictures in Fig. $4 \mathrm{~b}, \mathrm{c}$ are provided as Source Data files. All source data are available from the corresponding author (S.K.E.) by request. Source data are provided with this paper.

Received: 23 October 2019; Accepted: 30 April 2020;

Published online: 18 June 2020

\section{References}

1. Banerjee, D. et al. Potential of metal-organic frameworks for separation of xenon and krypton. Acc. Chem. Res. 48, 211-219 (2015).

2. Banerjee, D., Simon, C. M., Elsaidi, S. K., Haranczyk, M. \& Thallapally, P. K. Xenon gas separation and storage using metal-organic frameworks. Chem $\mathbf{4}$, 466-494 (2018).

3. Riley, B. J., Vienna, J. D., Strachan, D. M., McCloy, J. S. \& Jerden, J. L. Materials and processes for the effective capture and immobilization of radioiodine: a review. J. Nucl. Mater. 470, 307-326 (2016).

4. Zhang, X. et al. Confinement of iodine molecules into triple-helical chains within robust metal-organic frameworks. J. Am. Chem. Soc. 139, 16289-16296 (2017).

5. Soelberg, N. R. et al. Radioactive iodine and krypton control for nuclear fuel reprocessing facilities. Sci. Technol. Nucl. Ins. 2013, 1-12 (2013).

6. Banerjee, D. et al. Metal-organic framework with optimally selective xenon adsorption and separation. Nat. Commun. 7, 11831 (2016).

7. Mohamed, M. H. et al. Hybrid ultra-microporous materials for selective xenon adsorption and separation. Angew. Chem. Int. Ed. 55, 8285-8289 (2016).

8. Elsaidi, S. K. et al. Effect of ring rotation upon gas adsorption in SIFSIX-3-M $(\mathrm{M}=\mathrm{Fe}, \mathrm{Ni})$ pillared square grid networks. Chem. Sci. 8, 2373-2380 (2017).

9. Chen, X. et al. Direct observation of Xe and $\mathrm{Kr}$ adsorption in a Xe-selective microporous metal-organic framework. J. Am. Chem. Soc. 137, 7007-7010 (2015).

10. Wu, T., Feng, X., Elsaidi, S. K., Thallapally, P. K. \& Carreon, M. A. Zeolitic imidazolate framework-8 (ZIF-8) membranes for $\mathrm{Kr} / \mathrm{Xe}$ separation. Ind. Eng. Chem. Res. 56, 1682-1686 (2017).

11. Hulvey, Z. et al. Noble gas adsorption in copper trimesate, HKUST-1: an experimental and computational study. J. Phys. Chem. C. 117, 20116-20126 (2013).

12. Perry, J. J. et al. Noble gas adsorption in metal-organic frameworks containing open metal sites. J. Phys. Chem. C. 118, 11685-11698 (2014).

13. Liu, J., Strachan, D. M. \& Thallapally, P. K. Enhanced noble gas adsorption in Ag@MOF-74Ni. Chem. Commun. 50, 466-468 (2014).

14. Fernandez, C. A., Liu, J., Thallapally, P. K. \& Strachan, D. M. Switching $\mathrm{Kr} / \mathrm{Xe}$ selectivity with temperature in a metal-organic framework. J. Am. Chem. Soc. 134, 9046-9049 (2012).

15. Wang, H. et al. The first example of commensurate adsorption of atomic gas in a MOF and effective separation of xenon from other noble gases. Chem. Sci. 5, 620-624 (2014).

16. Bae, Y.-S. et al. High xenon/krypton selectivity in a metal-organic framework with small pores and strong adsorption sites. Micropor. Mesopor. Mat. 169, 176-179 (2013).

17. Kancharlapalli, S., Natarajan, S. \& Ghanty, T. K. Confinement-directed adsorption of noble gases (Xe/Kr) in MFM-300(M)-based metal-organic framework materials. J. Phys. Chem. C. 123, 27531-27541 (2019).

18. Banerjee, D., Elsaidi, S. K. \& Thallapally, P. K. Xe adsorption and separation properties of a series of microporous metal-organic frameworks (MOFs) with V-shaped linkers. J. Mater. Chem. A 5, 16611-16615 (2017).

19. Liu, J., Thallapally, P. K. \& Strachan, D. Metal-organic frameworks for removal of Xe and $\mathrm{Kr}$ from nuclear fuel reprocessing plants. Langmuir 28, 11584-11589 (2012).

20. Liu, J. et al. A two-column method for the separation of $\mathrm{Kr}$ and $\mathrm{Xe}$ from process off-gases. Ind. Eng. Chem. Res. 53, 12893-12899 (2014).

21. Forrest, $\mathrm{K}$. A. et al. Investigating $\mathrm{CO}_{2}$ sorption in SIFSIX-3-M $(\mathrm{M}=\mathrm{Fe}, \mathrm{Co}$, $\mathrm{Ni}, \mathrm{Cu}, \mathrm{Zn}$ ) through computational studies. Cryst. Growth Des. 19, 3732-3743 (2019).
22. Lee, S.-J. et al. Adsorptive separation of xenon/krypton mixtures using a zirconium-based metal-organic framework with high hydrothermal and radioactive stabilities. J. Hazard. Mater. 320, 513-520 (2016).

23. Cadiau, A. et al. Hydrolytically stable fluorinated metal-organic frameworks for energy-efficient dehydration. Science 356, 731-735 (2017).

24. Cui, X. L. et al. Pore chemistry and size control in hybrid porous materials for acetylene capture from ethylene. Science 353, 141-144 (2016).

25. Cadiau, A., Adil, K., Bhatt, P. M., Belmabkhout, Y. \& Eddaoudi, M. A metalorganic framework-based splitter for separating propylene from propane. Science 353, 137-140 (2016)

26. Kanoo, $\mathrm{P}$. et al. Unusual room temperature $\mathrm{CO}_{2}$ uptake in a fluorofunctionalized MOF: insight from Raman spectroscopy and theoretical studies. Chem. Commun. 48, 8487-8489 (2012).

27. Nugent, P. et al. Porous materials with optimal adsorption thermodynamics and kinetics for $\mathrm{CO}_{2}$ separation. Nature 495, 80-84 (2013).

28. Uemura, K., Maeda, A., Maji, T. K., Kanoo, P. \& Kita, H. Syntheses, crystal structures and adsorption properties of ultramicroporous coordination polymers constructed from hexafluorosilicate ions and pyrazine. Eur. J. Inorg. Chem. 2009, 2329-2337 (2009).

29. Elsaidi, S. K. et al. Hydrophobic pillared square grids for selective removal of $\mathrm{CO}_{2}$ from simulated flue gas. Chem. Commun. 51, 15530-15533 (2015).

30. Shekhah, O. et al. Made-to-order metal-organic frameworks for trace carbon dioxide removal and air capture. Nat. Commun. 5, 4228 (2014).

31. Yamamoto, T. \& Ootsuka, N. Radiation damage of fluorocarbon by krypton85 beta-rays, (4). J. Nucl. Sci. Technol. 19, 903-917 (1982).

32. Chen, L. et al. Separation of rare gases and chiral molecules by selective binding in porous organic cages. Nat. Mat. 13, 954 (2014).

33. Allen, F. The Cambridge Structural Database: a quarter of a million crystal structures and rising. Acta Cryst. B 58, 380-388 (2002).

34. Desveaux, B. E. et al. $\mathrm{CO}_{2}$ behavior in a highly selective ultramicroporous framework: insights from single-crystal X-ray diffraction and solid-state nuclear magnetic resonance spectroscopy. J. Phys. Chem. C. 123, 17798-17807 (2019).

35. Winger, K., Feichter, J., Kalinowski, M. B., Sartorius, H. \& Schlosser, C. A new compilation of the atmospheric 85krypton inventories from 1945 to 2000 and its evaluation in a global transport model. J. Environ. Radioact. 80, 183-215 (2005).

36. Moormann, R., Kemp, R. S. \& Li, J. Caution is needed in operating and managing the waste of new pebble-bed nuclear reactors. Joule 2, 1911-1914 (2018).

37. Banerjee, D. et al. Metal-organic framework with optimally selective xenon adsorption and separation. Nat. Commun. 7, ncomms11831 (2016).

38. Thallapally, P. K., Grate, J. W. \& Motkuri, R. K. Facile xenon capture and release at room temperature using a metal-organic framework: a comparison with activated charcoal. Chem. Commun. 48, 347-349 (2012).

39. Munakata, K., Yamatsuki, S., Tanaka, K. \& Fukumatsu, T. Screening test of adsorbents for recovery of krypton. J. Nucl. Sci. Technol. 37, 84-89 (2000).

\section{Acknowledgements}

Authors would like to thank DOE Office of Nuclear Energy for programmatic funding In particular we thank Dr. Terry Todd (INL), Dr. John Vienna (PNNL), Dr. Robert Jubin (ORNL), Dr. Kimberly Gray (DOE HQ), and Dr. Patricia Paviet (DOE HQ) for programmatic support. Pacific Northwest National Laboratory is a multiprogramming national laboratory operated for the U.S. Department of Energy by Battelle Memorial Institute under Contract DE-AC05-76RL01830. J.L. acknowledges support from the DOE Office of Nuclear Energy's NEUP Program under Grant No. DE-NE0008827. T.P. and B.S. acknowledge the National Science Foundation (Award No. DMR-1607989), including support from the Major Research Instrumentation Program (Award No. CHE-1531590). Computational resources were made available by a XSEDE Grant (No. TG-DMR090028) and by Research Computing at the University of South Florida. The authors would like to thank Dr. Wenqian Xu (ANL) for the helpful suggestions and Michael Gipple (NETL) for his assistance with the figures graphic.

\section{Author contributions}

S.K.E., M.H.M., J.L., P.T., and D.H. conceived the idea and supervised the project. S.K.E designed and performed the experiments and collected the data related to materials synthesis and characterization, gas sorption and breakthrough experiments. A.S.H. and M.G. performed the irradiation study and the associated PXRD experiments and their interpretation. T.P., S.S., and B.S. performed the modeling studies and the theoretical calculations. S.K.E., M.H.M., and A.S.H. involved in the analyses and interpretation of data. S.K.E. and M.H.M. wrote the paper with the help of J.L., P.T., T.P., B.S., and D.H.

\section{Competing interests}

The authors declare no competing interests. 


\section{Additional information}

Supplementary information is available for this paper at https://doi.org/10.1038/s41467020-16647-1.

Correspondence and requests for materials should be addressed to S.K.E., P.K.T. or J.L.

Peer review information Nature Communications thanks Tapan Ghanty and other, anonymous, reviewers for their contributions to the peer review of this work. Peer review reports are available.

Reprints and permission information is available at http://www.nature.com/reprints

Publisher's note Springer Nature remains neutral with regard to jurisdictional claims in published maps and institutional affiliations. (c) (i) Open Access This article is licensed under a Creative Commons Attribution 4.0 International License, which permits use, sharing, adaptation, distribution and reproduction in any medium or format, as long as you give appropriate credit to the original author(s) and the source, provide a link to the Creative Commons license, and indicate if changes were made. The images or other third party material in this article are included in the article's Creative Commons license, unless indicated otherwise in a credit line to the material. If material is not included in the article's Creative Commons license and your intended use is not permitted by statutory regulation or exceeds the permitted use, you will need to obtain permission directly from the copyright holder. To view a copy of this license, visit http://creativecommons.org/ licenses/by/4.0/.

(C) The Author(s) 2020 